\title{
Effect of the Glucagon-like Peptide-1 Receptor (GLP-1R) Agonists on Autonomic Function in Subjects With Diabetes: a Systematic Review and Meta-analysis.
}

\author{
Carla Greco ( $\nabla$ carlagreco@unimore.it ) \\ Department of Biomedical, Metabolic and Neural Sciences, University of Modena and Reggio Emilia, Modena, Italy. \\ Daniele Santi \\ Department of Biomedical, Metabolic and Neural Sciences, University of Modena and Reggio Emilia, Modena, Italy. \\ Giulia Brigante \\ Department of Biomedical, Metabolic and Neural Sciences, University of Modena and Reggio Emilia, Modena, Italy. \\ Chiara Pacchioni \\ Unit of Endocrinology, Department of Medical Specialties, Azienda Ospedaliero-Universitaria di Modena, Ospedale Civile di \\ Baggiovara, Modena, Italy. \\ Manuela Simoni \\ Department of Biomedical, Metabolic and Neural Sciences, University of Modena and Reggio Emilia, Modena, Italy.
}

\section{Research Article}

Keywords: diabetes mellitus, glucagon-like peptide-1 receptor agonist, heart rate, autonomic nervous system, diabetic autonomic neuropathy

Posted Date: February 26th, 2021

DOI: https://doi.org/10.21203/rs.3.rs-244365/v1

License: () (1) This work is licensed under a Creative Commons Attribution 4.0 International License. Read Full License

Version of Record: A version of this preprint was published at Diabetes \&amp; Metabolism Journal on April 12th, 2022. See the published version at https://doi.org/10.4093/dmj.2021.0314. 


\section{Abstract}

Background. In addition to the metabolic effects in diabetes, glucagon-like peptide 1 receptor (GLP-1R) agonists lead to a small but substantial increase in heart rate (HR). However, the GLP-1R actions on the autonomic nervous system (ANS) in people with diabetes remain still debated. Therefore, this meta-analysis evaluates the effect of GLP-1R agonist chronic treatment on measures of ANS function in people with diabetes.

Methods. According to the Cochrane Collaboration and PRISMA statement, we conducted a meta-analysis considering clinical trials in which the autonomic function was evaluated in people with diabetes chronically treated with GLP-1R agonists. The outcomes were the change of ANS function measured by heart rate variability (HRV) and cardiac autonomic reflex tests (CARTs).

Results. In the studies enrolled, HR significantly increased after treatment $(\mathrm{p}<0.001)$, whereas low frequency/high frequency ratio did not differ $(p=0.410)$; no changes in other measures of HRV were detected. Considering CARTs, only the 30:15 value derived from lying-to-standing test was significantly lower after treatment $(p=0.002)$, but only two studies reported this measurement. No differences in other CARTs outcome were observed.

Conclusion. The present meta-analysis confirms the HR increase but seems to exclude an alteration of the sympatho-vagal balance due to chronic treatment with GLP-1R agonists in diabetes, considering the available measures of ANS function.

\section{Introduction}

The diabetic autonomic neuropathy (DAN) is defined as a heterogeneous category of disorders of the autonomic nervous system (ANS) in individuals with either diabetes mellitus (DM) or metabolic derangements of pre-diabetes, when other potential causes have been excluded ${ }^{1}$. In particular, the cardiac autonomic neuropathy (CAN) is the manifestation of an ANS imbalance, due to the impairment of autonomic control of the cardiovascular system ${ }^{1,2}$. CAN affects at least $20 \%$ of unselected patients, and this incidence raises up to $65 \%$ of subjects with either increasing age or long diabetes duration ${ }^{2-4}$. However, the actual CAN prevalence varies, depending upon diagnostic criteria, patient cohort, and testing modality 2,5 . According to standard cardiovascular reflex tests (CARTs), the CAN prevalence is reported about 7\% in type 2 DM (T2DM) and increases with diabetes duration by $4.6-6 \%$ per year $^{2,5}$. It is well known that CAN incidence is influenced by diabetic disease duration, patient age, glycaemic control, and concomitant metabolic syndrome features ${ }^{6,7}$. The CAN diagnosis in people with diabetes is extremely relevant, influencing the prognosis for cardiovascular morbidity and predicting the overall cardiovascular risk ${ }^{8}$. Indeed, CAN is related to silent myocardial ischemia, stroke, postural hypotension, exercise intolerance and enhanced intraoperative instability

9 . Therefore, from a clinical perspective, an individual with diabetes and CAN is at higher risk of mortality and of cardiovascular complications with heavy impact on morbidity and prognosis.

Glucagon-like peptide 1 receptor (GLP-1R) agonists represent a relatively new class of anti-hyperglycemic agents, addressing most of the pathophysiological mechanisms involved in the development of T2DM. The main GLP-1R agonist actions are the stimulation of insulin secretion, the inhibition of glucagon secretion, the delay of the gastric emptying time and the stimulation of neogenesis of insulin-secreting cells ${ }^{10}$. Moreover, GLP-1R agonists show favourable effects on body weight and metabolic profile, with a lower risk of hypoglycaemia. Moreover, the favourable effects on body weight and metabolic profile, together with a reduction in blood pressure (BP), contribute to reduce the cardiovascular risk. For all these reasons, the GLP1-R agonist use is constantly increasing to treat T2DM.

Among beneficial GLP-1R agonist effects, heart rate (HR) increase has been observed. Despite the resting HR increase could be considered a safety concern ${ }^{11}$, GLP-1R agonist administration is associated to major adverse cardiovascular events (MACE) reduction, including stroke, cardiovascular and all-cause mortality, as suggested by the cardiovascular outcome trials (CVOTs) 12-18 (Table 1). This GLP-1R agonist favourable effect on cardio-metabolic health is becoming increasingly evident, although the underlying mechanisms remain largely unknown. Improvement of hypertension ${ }^{19}$, endothelial function 20 and a natriuretic 
GLP-1R agonist-related effect ${ }^{21}$ have been proposed. However, while a small but substantial increase in HR by about 3 bpm has been reported by the majority of the available trials ${ }^{22}$, action of GLP-1R agonists on autonomic function in diabetes remains still debated. With this in mind, it is clear that the GLP-1R agonist effects on HR and on ANS need to be reconciled with the favourable cardiovascular outcomes in clinical trials. Thus, we performed this meta-analysis with the main aim to highlight the GLP-1R agonist actions on available measures of autonomic function in diabetic people.

Table 1

Hazard ratio $(\mathrm{HR}, 95 \% \mathrm{Cl})$ of the primary composite outcome and secondary outcomes reported in the cardiovascular outcome trials (CVOTs).

\begin{tabular}{|c|c|c|c|c|c|c|c|}
\hline CVOT & LEADER & ELIXA & SUSTAIN-6 & EXSCEL & HARMONY & REWIND & PIONEER-6 \\
\hline GLP-1R & liraglutide & lixisenatide & semaglutide & exenatide & albiglutide & dulaglutide & semaglutide os \\
\hline agonist & 12 & & $\mathrm{sc}^{14}$ & & 16 & & \\
\hline \multirow{2}{*}{$\begin{array}{l}\text { Composite } \\
\text { MACE* }\end{array}$} & 0.87 & 1.02 & 0.74 & 0.91 & 0.78 & 0.88 & 0.79 \\
\hline & $\begin{array}{l}(0.78- \\
0.97)\end{array}$ & $\begin{array}{l}(0.89- \\
1.17)\end{array}$ & $(0.58-0.95)$ & $\begin{array}{l}(0.83- \\
1.00)\end{array}$ & $\begin{array}{l}(0.68- \\
0.90)\end{array}$ & $\begin{array}{l}(0.79- \\
0.99)\end{array}$ & $(0.57-1.11)$ \\
\hline \multirow[t]{2}{*}{ CV death } & 0.78 & 0.98 & 0.98 & 0.88 & 0.93 & 0.91 & 0.49 \\
\hline & $\begin{array}{l}(0.66- \\
0.93)\end{array}$ & $\begin{array}{l}(0.87- \\
1.22)\end{array}$ & $(0.65-1.48)$ & $\begin{array}{l}(0.76- \\
1.02)\end{array}$ & $\begin{array}{l}(0.73- \\
1.19)\end{array}$ & $\begin{array}{l}(0.78- \\
1.06)\end{array}$ & $(0.27-0.92)$ \\
\hline \multirow[t]{2}{*}{ Nonfatal MI } & 0.88 & $1.03^{* *}$ & 0.74 & $0.97^{\star \star}$ & $0.75^{\star \star}$ & 0.96 & 1.18 \\
\hline & $\begin{array}{l}(0.75- \\
1.03)\end{array}$ & $\begin{array}{l}(0.87- \\
1.22)\end{array}$ & $(0.51-1.08)$ & $\begin{array}{l}(0.85- \\
1.10)\end{array}$ & $\begin{array}{l}(0.61- \\
0.90)\end{array}$ & $\begin{array}{l}(0.79- \\
1.16)\end{array}$ & $(0.73-1.90)$ \\
\hline \multirow{2}{*}{$\begin{array}{l}\text { Hospitalization } \\
\text { HF }\end{array}$} & 0.87 & 0.96 & 1.11 & 0.94 & $0.85^{\star \star \star}$ & 0.93 & 0.86 \\
\hline & $\begin{array}{l}(0.73- \\
1.05)\end{array}$ & $\begin{array}{l}(0.75- \\
1.23)\end{array}$ & $(0.77-1.61)$ & $\begin{array}{l}(0.78- \\
1.13)\end{array}$ & $\begin{array}{l}(0.70- \\
1.04)\end{array}$ & $\begin{array}{l}(0.77- \\
1.12)\end{array}$ & $(0.48-1.55)$ \\
\hline \multirow[t]{2}{*}{ Stroke } & 0.89 & 1.12 & 0.61 & $0.85^{\star \star}$ & $0.86 \star \star$ & 0.76 & 0.74 \\
\hline & $\begin{array}{l}(0.72- \\
1.11)\end{array}$ & $\begin{array}{l}(0.79- \\
1.58)\end{array}$ & $(0.38-0.99)$ & $\begin{array}{l}(0.70- \\
1.03)\end{array}$ & $\begin{array}{l}(0.66- \\
1.14)\end{array}$ & $\begin{array}{l}(0.61- \\
0.95)\end{array}$ & $(0.35-1.57)$ \\
\hline \multirow{2}{*}{$\begin{array}{l}\text { All-cause } \\
\text { mortality }\end{array}$} & 0.85 & 0.94 & 1.05 & 0.86 & 0.95 & 0.90 & 0.51 \\
\hline & $\begin{array}{l}(0.74- \\
0.97)\end{array}$ & $\begin{array}{l}(0.78- \\
1.13)\end{array}$ & $(0.74-1.5)$ & $\begin{array}{l}(0.77- \\
0.97)\end{array}$ & $\begin{array}{l}(0.79- \\
1.16)\end{array}$ & $\begin{array}{l}(0.80- \\
1.01)\end{array}$ & $(0.31-0.84)$ \\
\hline
\end{tabular}

* In LEADER, SUSTAIN-6, EXSCEL, HARMONY, REWIND and PIONEER-6 trials composite MACE was three-component outcome defined by the first occurrence of death from cardiovascular causes, nonfatal myocardial infarction, or nonfatal stroke. In ELIXA trial, primary end point (MACE plus) was the first occurrence of death from cardiovascular causes, nonfatal stroke, nonfatal myocardial infarction or unstable angina.

** fatal and nonfatal.

${ }^{* *}$ Composite of death from cardiovascular causes or hospital admission for heart failure.

Abbreviations: CVOT, cardiovascular outcome trial; CV, cardiovascular; GLP-1R agonist, glucagon-like peptide 1 receptor; HF, heart failure; MACE, major adverse cardiac events; MI, myocardial infarction

\section{Materials And Methods}

This meta-analysis was performed according to the Cochrane Collaboration and PRISMA statement. To ensure originality and transparency of the review process, the meta-analysis was a priori registered in the International Prospective Register of Systematic Reviews (PROSPERO; registration number CRD42020218063). The literature search was performed until November 10th, 2020 considering the following string: (((autonomic function)) OR ((autonomic dysfunction)) OR (cardiac autonomic 
neuropathy) AND (((((((GLP-1 receptor agonist)) OR (GLP-1R agonist)) OR (semaglutide)) OR (liraglutide)) OR (exenatide)) OR (lixisenatide) OR (dulaglutide)) OR (albiglutide). Medline, Embase and Cochrane databases were considered.

All available GLP-1R agonists were considered potentially eligible, whether applied in clinical trial aiming at evaluating autonomic function before and after chronic administration in participants with diabetes. Thus, each parameter of autonomic function was considered before and after chronic treatment in the study groups. Moreover, when available, mean parameters were compared between study and control groups after treatment.

\section{Endpoints}

CARTs represent the gold standard in autonomic testing ${ }^{2,23}$. CARTs involve measuring autonomic responses through changes in HR and blood pressure (BP) to provocative physiological manoeuvres. The standard CARTs recommended for diagnosis of CAN include: the deep breathing (DB) test (expiration/inspiration ratio, E/I ratio), the lying-to-standing (LS) test (30:15), the Valsalva manoeuvre (VM) and the BP response to standing ${ }^{2}$. E/I index from DB test represents the ratio between the 3 maximum and the 3 minimum RR intervals (the intervals between two consecutive eletrocardiogram R waves) in a cycle of expiration and inspiration. In LS test the maximum/minimum 30:15 value is the ratio of the longest RR interval measured between the 25th and 35th beat after the change of posture and the shortest RR interval measured between the 10th and 20th beat. The Valsalva manoeuvre test indicates the ratio between the longest RR interval after exhalation and the shortest RR interval during exhalation. Other approaches in clinical research are currently available to evaluate CAN such as heart rate variability (HRV), baroreflex sensitivity, muscle sympathetic nerve activity, heart sympathetic imaging ${ }^{24}$. Non-invasive and widely used in clinical research, HRV provides key information about autonomic - parasympathetic and sympathetic modulation of the cardio-vascular system. The measurement of HRV includes two domains. In the frequency domain, the components of the HRV obtained by spectral analysis consist of low frequency (LF) and high frequency (HF) indices. These indices provide information about both the sympathetic and parasympathetic influences on heart. Thus, the LF/HF ratio is the index of sympathetic-parasympathetic balance. Time domain measures of the normal RR intervals mainly include differences between the longest and the shortest RR intervals, the standard deviations of RR intervals (SDNN), and the square root of the mean squared difference of successive RR intervals (RMSSD) ${ }^{24}$.

\section{Study selection and inclusion criteria}

The literature search evaluated all clinical trials with the following inclusion criteria: i) either interventional or observational, ii) in which the autonomic function was evaluated, iii) in people with diabetes, iv) treated with GLP-1R agonists. In particular, change of autonomic nervous system function before and after chronic GLP-1R agonist treatment using measures of heart rate variability was considered the main outcome. Treatment was considered chronic when GLP-1R agonist was administered for more than 4 weeks. Both participants with type 1 and type 2 DM were considered eligible. Randomization and presence of controls were not considered as inclusion criteria.

\section{Data collection process and quality}

Two authors (CG and DS) separately performed the literature search, collecting abstracts of each study. Each abstract was evaluated for inclusion criteria and data were extracted from each study considered eligible. CG and DS performed quality control checks on extracted data. For the literature search, the primary endpoint was the LF/HF ratio after chronic GLP-1R agonist administration. Secondary endpoints extracted were: HR, SDNN and RSMSSD as measures of HRV and E/I ratio, 30:15, VM as parameters of CARTs.

The risk of bias was assessed independently by two investigators (CG and DS), using Cochrane risk-of-bias algorithm. In particular, the following criteria were considered for each included trial, (i) randomization method, (ii) concealment of allocation, (iii) presence or absence of blinding to treatment allocation, (iv) presence or absence of blinding of outcome assessment, (v) potential incomplete data biases and (vi) reporting biases.

\section{Data synthesis and analysis}


Using the Review Manager (RevMan) 5.4 Software (Version 5.4.1 Copenhagen: The Nordic Cochrane Centre, The Cochrane Collaboration, 2014), continuous variables were comprehensively evaluated as inverse variance of mean variables. When data were reported in the original manuscript as median or logarithm, they were transformed in mean \pm standard deviation. Indeed, mean \pm standard deviation is required for the meta-analytic approach. However, since these parameters could be obtained using different approaches, the meta-analyses were performed using standard mean difference. Considering that studies included in the meta-analysis reported different treatment durations and different time-points in which endpoints were evaluated, we considered the last available time point for each trial (median 24 weeks; min 12 - max 72 weeks). The degree of heterogeneity among the studies included in each analysis was examined by inspecting both the scatter in the data points and the overlap in their confidence intervals (Cls), and by performing $\mathrm{I}^{2}$ statistics. The inverse variance with the fixed model was initially chosen, whereas the random effect model was preferred in case of $\mathrm{I}^{2}$ higher than $60 \%$. Sensitivity analyses were performed, considering the type of diabetes and the GLP-1R agonist used, when possible. Values of $p<0.05$ were considered statistically significant.

\section{Results}

596 manuscripts were identified by the literature search (Fig. 1). After abstract evaluations, 16 studies were considered for the full text analysis (Fig. 1). Among these, ten studies were excluded (reasons reported in Fig. 1) and six studies were enrolled ${ }^{25-}$

30 in the final analysis (Fig. 1). Table 2 summarizes the characteristics of the studies included in the meta-analysis. Moreover, Table 3 shows the characteristics of the patient cohorts included in the analysis: a total of 182 individuals with diabetes were enrolled (112 men and 72 women), with a mean age of $54.68 \pm 10.7$ years. Only two studies enrolled patients with type 1 diabetes mellitus. 
Table 2

General characteristics of the six included studies.

\begin{tabular}{|c|c|c|c|c|c|c|c|}
\hline AUTHOR & $\begin{array}{l}\text { STUDY } \\
\text { DESIGN }\end{array}$ & SUBJECTS & TREATMENT & CONTROL & $\begin{array}{l}\text { FOLLOW } \\
\text { UP }\end{array}$ & OUTCOME & RESULTS \\
\hline \multirow[t]{2}{*}{$\begin{array}{l}\text { Jaiswal M }{ }^{28} \\
2015\end{array}$} & \multirow[t]{2}{*}{$\begin{array}{l}\text { Open-label } \\
\text { randomized, } \\
\text { controlled }\end{array}$} & \multirow[t]{2}{*}{$46 \mathrm{~T} 2 \mathrm{D}$} & \multirow[t]{2}{*}{$\begin{array}{l}\text { daily } \\
\text { exenatide }\end{array}$} & \multirow[t]{2}{*}{ glargine } & \multirow[t]{2}{*}{$\begin{array}{l}12 \text { and } \\
18 \\
\text { months }\end{array}$} & $\begin{array}{l}\text { CARTs: DB } \\
\text { and VM } \\
\text { test; }\end{array}$ & $\begin{array}{l}\text { CARTs: no } \\
\text { changes E/I, VM. }\end{array}$ \\
\hline & & & & & & $\begin{array}{l}\text { HRV: HR, } \\
\text { LF/HF, } \\
\text { SDNN, } \\
\text { RMSSD. }\end{array}$ & $\begin{array}{l}\text { HRV: no changes } \\
\text { HR, LH/HF, } \\
\text { SDNN and } \\
\text { RMSSD. }\end{array}$ \\
\hline \multirow[t]{2}{*}{$\begin{array}{l}\text { Kumarathurai } \\
\text { P }^{31}, 2017\end{array}$} & \multirow[t]{2}{*}{$\begin{array}{l}\text { Double-blind } \\
\text { placebo } \\
\text { controlled }\end{array}$} & \multirow[t]{2}{*}{$30 \mathrm{~T} 2 \mathrm{D}$} & \multirow[t]{2}{*}{ liraglutide } & \multirow[t]{2}{*}{ placebo } & \multirow[t]{2}{*}{$\begin{array}{l}12 \\
\text { weeks }\end{array}$} & \multirow{2}{*}{$\begin{array}{l}\text { HRV: HR, } \\
\text { LF/HF, } \\
\text { SDNN, } \\
\text { RMSSD. }\end{array}$} & 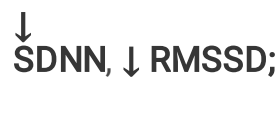 \\
\hline & & & & & & & $\begin{array}{l}\uparrow \mathrm{HR}, \downarrow \mathrm{HF},= \\
\text { LF/HF. }\end{array}$ \\
\hline \multirow[t]{3}{*}{$\begin{array}{l}\text { Cacciatori V } \\
26,2018\end{array}$} & \multirow[t]{3}{*}{$\begin{array}{l}\text { Observational } \\
\text { study }\end{array}$} & \multirow[t]{3}{*}{$28 \mathrm{~T} 2 \mathrm{D}$} & \multirow[t]{3}{*}{ exenatide ER } & \multirow[t]{3}{*}{ no control } & \multirow[t]{3}{*}{$\begin{array}{l}3 \text { and } 6 \\
\text { months }\end{array}$} & \multirow{2}{*}{$\begin{array}{l}\text { HRV (lying } \\
\text { and } \\
\text { standing } \\
\text { positions): } \\
\text { HR, } \\
\text { LF/HF; }\end{array}$} & $\begin{array}{l}\text { HRV: } \uparrow \mathrm{HR} ; \downarrow L L F ; \\
=\mathrm{HF} ; \downarrow L F / H F\end{array}$ \\
\hline & & & & & & & $\begin{array}{l}\text { CARTs: no } \\
\text { change LS, DB } \\
\text { and VM. }\end{array}$ \\
\hline & & & & & & \multicolumn{2}{|l|}{$\begin{array}{l}\text { CARTs: } \\
\text { LS, DB } \\
\text { and VM. }\end{array}$} \\
\hline $\begin{array}{l}\text { Nyström T }{ }^{30}, \\
2019\end{array}$ & $\begin{array}{l}\text { Open-label } \\
\text { randomized, } \\
\text { controlled }\end{array}$ & 62 T2D & liraglutide & glimepiride & $\begin{array}{l}18 \\
\text { weeks }\end{array}$ & $\begin{array}{l}\text { HRV: HR, } \\
\text { LF/HF, } \\
\text { SDNN, } \\
\text { RMSSD. }\end{array}$ & $\begin{array}{l}\uparrow \text { HR; no } \\
\text { changes LF, HF, } \\
\text { SDNN and } \\
\text { RMSSD. }\end{array}$ \\
\hline \multirow{2}{*}{$\begin{array}{l}\text { Brock C 25, } \\
2019\end{array}$} & \multirow{2}{*}{$\begin{array}{l}\text { Double-blind } \\
\text { placebo } \\
\text { controlled }\end{array}$} & \multirow[t]{2}{*}{39 T1D } & \multirow[t]{2}{*}{ liraglutide } & \multirow[t]{2}{*}{ placebo } & \multirow[t]{2}{*}{$\begin{array}{l}26 \\
\text { weeks }\end{array}$} & \multirow{2}{*}{$\begin{array}{l}\text { HRV: HR, } \\
\text { LF/HF, } \\
\text { SDNN, } \\
\text { RMSSD. }\end{array}$} & \multirow{2}{*}{$\begin{array}{l}\text { No changes HR, } \\
\text { LF, HF, SDNN } \\
\text { and RMSSD. }\end{array}$} \\
\hline & & & & & & & \\
\hline $\begin{array}{l}\text { Hansen CS } \\
27 \\
2019\end{array}$ & $\begin{array}{l}\text { Double-blind } \\
\text { placebo } \\
\text { controlled }\end{array}$ & 99 T1D & liraglutide & placebo & $\begin{array}{l}24 \\
\text { weeks }\end{array}$ & $\begin{array}{l}\text { HRV: } \\
\text { LF/HF, } \\
\text { SDNN, } \\
\text { RMSSD. }\end{array}$ & $\begin{array}{l}\uparrow \text { HR; no } \\
\text { changes SDNN, } \\
\text { RMSSD, HF, LF, } \\
\text { HF/LF ratio. }\end{array}$ \\
\hline & & & & & & $\begin{array}{l}\text { CARTs: } \\
\text { LS, DB } \\
\text { and VM } \\
\text { test. }\end{array}$ & $\begin{array}{l}\text { No changes E/I, } \\
30: 15 \text { and VM. }\end{array}$ \\
\hline $\begin{array}{l}\text { Abbreviations: } \\
\text { release; HF, hig } \\
\text { mean square o } \\
\text { type } 2 \text { diabetes }\end{array}$ & $\begin{array}{l}R T S, \text { cardiova } \\
\text { requency; HR } \\
\text { uccessive dif } \\
M, \text { Valsalva r }\end{array}$ & $\begin{array}{l}\text { ar reflex tes } \\
\text { t rate; HRV } \\
\text { ces; SDNN, } \\
\text { euvre. }\end{array}$ & $\begin{array}{l}\text { B, deep bre } \\
\text { it rate varia }\end{array}$ & $\begin{array}{l}g ; E / I \text { rati } \\
; L F \text {, low } f \\
\text { f beat-to- }\end{array}$ & $\begin{array}{l}\text { xpiratiol } \\
\text { uency; } L \\
\text { t (NN) it }\end{array}$ & $\begin{array}{l}\text { iration ra } \\
g \text {-to-stan } \\
\text { Is: T1D, } t\end{array}$ & $\begin{array}{l}\text { ER, extended } \\
\text { g; RMSSD, root } \\
1 \text { diabetes; T2D, }\end{array}$ \\
\hline
\end{tabular}


Table 3

General characteristics of the cohorts included in the analysis.

\begin{tabular}{|c|c|c|c|c|c|c|c|}
\hline AUTHOR & $\begin{array}{l}\text { TYPE OF } \\
\text { DIABETES }\end{array}$ & $\begin{array}{l}\text { SUBJECTS } \\
\text { (number) }\end{array}$ & GENDER & $\begin{array}{l}\text { AGE } \\
\text { (mean } \\
+ \text { SD) }\end{array}$ & MOLECULE & DOSAGE & $\begin{array}{l}\text { TREATMENT } \\
\text { DURATION }\end{array}$ \\
\hline $\begin{array}{l}\text { Jaiswal M } 28 \\
2015\end{array}$ & $\mathrm{~T} 2 \mathrm{D}$ & 22 & $13 \mathrm{M}, 9 \mathrm{~F}$ & $51 \pm 13$ & exenatide & $\begin{array}{l}10 \mu \mathrm{g} \\
\text { twice } \\
\text { daily }\end{array}$ & 18 months \\
\hline $\begin{array}{l}\text { Kumarathurai P } \\
31,2017\end{array}$ & $\mathrm{~T} 2 \mathrm{D}$ & 30 & NR & NR & liraglutide & $\begin{array}{l}1.8 \mathrm{mg} \\
\text { daily }\end{array}$ & 12 weeks \\
\hline $\begin{array}{l}\text { Cacciatori V } 26 \\
2018\end{array}$ & $\mathrm{~T} 2 \mathrm{D}$ & 28 & $\begin{array}{l}13 \mathrm{M} \\
15 \mathrm{~F}\end{array}$ & $\begin{array}{l}62.9 \pm \\
9.6\end{array}$ & $\begin{array}{l}\text { exenatide } \\
\text { ER }\end{array}$ & $\begin{array}{l}2 \mathrm{mg} \text { once } \\
\text { weekly }\end{array}$ & 24 weeks \\
\hline $\begin{array}{l}\text { Nyström T }{ }^{30} \text {, } \\
2019\end{array}$ & $\mathrm{~T} 2 \mathrm{D}$ & 33 & $24 \mathrm{M}, 9 \mathrm{~F}$ & $\begin{array}{l}60.8 \pm \\
7.6\end{array}$ & liraglutide & $\begin{array}{l}1.8 \mathrm{mg} \\
\text { daily }\end{array}$ & 18 weeks \\
\hline Brock C ${ }^{25}, 2019$ & T1D & 19 & $17 \mathrm{M}, 2 \mathrm{~F}$ & $51 \pm 10$ & liraglutide & $\begin{array}{l}1.2-1.8 \\
\text { mg daily }\end{array}$ & 26 weeks \\
\hline $\begin{array}{l}\text { Hansen CS } 27, \\
2019\end{array}$ & T1D & 50 & $\begin{array}{l}30 \mathrm{M} \\
20 \mathrm{~F}\end{array}$ & $\begin{array}{l}47.7 \pm \\
13.3\end{array}$ & liraglutide & $\begin{array}{l}1.8 \mathrm{mg} \\
\text { daily }\end{array}$ & 24 weeks \\
\hline
\end{tabular}

Abbreviations: ER, extended release; $F$, females; $M$, males; T1D, type 1 diabetes; T2D, type 2 diabetes.

\section{Primary outcome}

The LF/HF ratio did not differ after treatment in the entire sample evaluated $(p=0.410)$, as well as considering exenatide $(p=$ $0.290)$ or liraglutide $(p=0.930)$ treatment, separately (Fig. 2$)$. This lack of LF/HF difference after treatment was maintained also dividing studies according to the type of diabetes considered (standard mean difference $-0.03 ; 95 \% \mathrm{Cl}:-0.26,0.20, \mathrm{I}^{2}=0 \%$, $p=0.080$ ) (Additional file 1: Supplementary Fig. 1). Thus, chronic treatment with GLP-1R agonists seems not to affect LF/HF, also after sensitivity analyses. This was further confirmed comparing study and control groups, showing no differences in the LF/HF ratio after treatment (mean difference $0.18 ; 95 \% \mathrm{Cl}:-0.66,1.01, \mathrm{I}^{2}=0 \%, \mathrm{p}=0.680$ ) (Additional file 1: Supplementary Fig. 2).

\section{Secondary outcomes}

HR was reported in all trials, for a total of 182 patients, evaluated before and after chronic treatment. The HR significantly increased after treatment $(p<0.001)$, with a low heterogeneity rate $(6 \%)$ (Fig. 3$)$. This significant improvement remained considering the use of liraglutide or exenatide separately (Fig. 3). Since Cacciatori et al. did not report a control group ${ }^{26}$, this study was excluded when study and control groups were compared post-treatment. In this analysis, HR was not significantly different between study and control groups (mean difference $-0.86 ; 95 \% \mathrm{Cl}:-3.26,1.55, \mathrm{I}^{2}=16 \%, \mathrm{p}=0.480$ ) (Additional file 1 : Supplementary Fig. 3).

After chronic treatment, SDNN did not significantly change (standard mean difference $0.08 ; 95 \% \mathrm{Cl}:-0.65,0.81, \mathrm{p}=0.830$ ) (Additional file 1: Supplementary Fig. 4). Considering the study-control comparison, significantly lower SDNN values were detected in the study- compared to control groups $(p=0.040)$ (Fig. 4).

RSMSSD was evaluated in six studies, showing no difference after treatment (standard mean difference $0.57 ; 95 \% \mathrm{Cl}$ : -0.41 , $1.55, \mathrm{I}^{2}=94 \%, \mathrm{p}=0.250$ ) (Additional file 1: Supplementary Fig. 5). Similarly, no difference between study-and control groups were detected (standard mean difference - 0.38; 95\% Cl: -1.20, 0.44, $\mathrm{p}=0.360$ ) (Additional file 1: Supplementary Fig. 6). 
The E/I ratio did not change after chronic GLP-1R agonist administration (mean difference $-1.13 ; 95 \% \mathrm{Cl}:-3.64,1.38, \mathrm{I}^{2}=95 \%, \mathrm{p}$ $=0.380$ ) (Additional file 1: Supplementary Fig. 7). In the study vs. control group comparison, the E/I ratio was not significantly different (mean difference0.0; 95\% Cl: -0-004, 0.004, $\mathrm{p}=0.999$ ) (Additional file 1: Supplementary Fig. 8).

The 30:15 value was significantly lower after treatment (standard mean difference $0.50 ; 95 \% \mathrm{Cl}: 0.18,0.83, \mathrm{p}=0.002$ ), although this result was obtained considering only two studies (Fig. 5). Only Hansen et al. reported LS mean difference in the comparison between study and control groups ${ }^{27}$, thus this analysis was not feasible.

The VM did not significantly change after treatment (mean difference $0.04 ; 95 \% \mathrm{Cl}:-0.08,0.15, \mathrm{p}=0.520$ ) (Additional file 1 : Supplementary Fig. 9).

Finally, the risk of bias was evaluated (Additional file 1: Supplementary Fig. 10), showing a good quality of the included studies, in terms of reporting and incomplete biases. On the contrary, a variable quality in terms of blinding was detected, reflecting the difficulty to perform a completely randomized, double-blind clinical trial in this setting.

\section{Discussion}

Here, we confirm that chronic GLP-1R agonist administration increases HR, according to a previously available meta-analysis 22. Systematically, the HR increase after chronic GLP-1R agonist administration is evident in five of six included trials. Indeed, only one study found no significant changes in HR after GLP-1R agonist administration, but, differently from the others, authors used a short-acting GLP-1R agonist, such as exenatide, for much longer time ${ }^{28}$. Thus, we could speculate that the GLP-1R agonist effect on HR could depend on the molecule used and the duration of the administration. Moreover, together with the HR increase, no significant change in other ANS-related parameters is evident in our meta-analysis. This result suggests that the chronic GLP-1R agonist administration may not influence the sympathetic and parasympathetic functions. Thus, we could speculate that the HR modifications induced by GLP-1R agonist is not consequence of sympathetic or parasympathetic stimulation, but other mechanisms should be involved.

GLP-1R agonists are increasingly used in clinical practice in diabetes, considering the wide range of positive effects on glucose homeostasis, body weight, BP and the low risk of hypoglycaemia. However, an overall GLP-1R agonist effect on ANS is far from being elucidated, even with the meta-analytic approach. Considering each study separately, interesting results could be extracted. Jaiswal et al. did not detect any change in autonomic function after 18 months of treatment with the short-acting GLP-1R agonist exenatide in patients with T2DM, evaluating either the gold-standard CARTs, such as DB and VM or measures of HRV, such as HR, LF/HF, SDNN, RMSSD ${ }^{28}$. In particular, that study was characterized by different follow-up length (18 months) than other studies included in the analysis (range 12-26 weeks). Therefore, we could not exclude that this difference represents a confounding factor, or a determinant of a kind of mitigation of HR increase over time. On the contrary, Kumarathurai et al. reported detrimental reductions in several HRV indices in T2DM patients treated with liraglutide for 12 weeks ${ }^{31}$. In particular, liraglutide decreased SDNN, RMSSD and HF without changes in LF/HF ratio compared to placebo ${ }^{31}$. This SDNN decrease persisted despite body weight loss and metabolic parameter improvement, suggesting an impairment in vagal activity after treatment ${ }^{31}$. Moreover, in order to elucidate the role of the cardiac sympatho-vagal balance as a possible mediator of the reported HR increase in GLP-1R agonist treatment, Cacciatori et al. performed CARTs and power spectral analysis of HRV in 28 T2DM patients after exenatide extended-release administration ${ }^{26}$. The main result of this study is an expected HR increase together with an unexpected LF/HF decrease, suggesting the existence of a compensatory mechanism 26. This phenomenon is characterized by a "shift" of the sympatho-vagal balance with reduction of the LF component and no change in parasympathetic tone (HF) ${ }^{26}$. In contrast, Nystrom et al. demonstrated the absence of changes in sympathetic or parasympathetic activity evaluated by HRV in 62 T2DM individuals receiving $1.8 \mathrm{mg}$ liraglutide once daily in comparison with 4 mg glimepiride once daily ${ }^{30}$. Similarly, in the context of type 1 DM (T1DM), changes neither in the HRV domains, nor in cardiac vagal tone and cardiac sensitivity to the baroreflex were observed in 19 patients treated with liraglutide for 26 weeks ${ }^{25}$. This result was confirmed by the post-hoc analysis of Hansen et al., showing no changes in CAN measures after liraglutide 1.8 mg once-daily for 24 weeks. In this study, the E/I ratio declined significantly in both liraglutide and placebo groups 27 . 
Accordingly, our findings show no difference in the LF/HF ratio after treatment, considering both different molecules (exenatide and/or liraglutide) and both type of diabetes (T1DM and/or T2DM). Moreover, others HRV measures, such as SDNN and RSMSSD, do not change after chronic GLP-1R agonist administration. These results are confirmed considering liraglutide and exenatide separately, suggesting no differences between molecules. LF/HF ratio represents an index widely used in clinical practice for CAN evaluation in diabetic patients, providing information about autonomic - parasympathetic and sympathetic modulation of the cardiovascular system. Even if considered among the methods of investigation for cardiac autonomic dysfunction in human research studies ${ }^{24}$, LF/HF ratio from HRV study confirms to be a measure not accurate and not directly related to sympatho-vagal balance, according to previous studies ${ }^{32,33}$. Among CARTs measurements, representing the gold standard for the diagnosis of CAN, the only parameter that seems to be influenced by GLP-1R agonist administration is the 30:15 ratio, which decreases after treatment. However, the strength of this result is limited by the small number of trials reporting this parameter. Thus, our meta-analysis suggests that chronic GLP-1R agonist treatment does not influence the sympatho-vagal balance in people with diabetes. Hence, the HR increase could depend on different mechanisms.

In animal models, GLP-1 engages GLP-1R in central, peripheral, and autonomic nervous systems, enhancing the sympathetic nervous system activity, and reducing the parasympathetic nervous system activity ${ }^{34}$. In this regard, Baggio et al. suggested that the GLP-1R agonist-related HR increase is the final effect of direct chronotropic action, which is attenuated by propanolol but not by atropine ${ }^{34}$. Moreover, the in vivo GLP-1R agonist administration induces $c$-fos expression - a marker of neuronal activity - in the adrenal medulla, activates neurons involved in autonomic control in the brain, and activates tyrosine hydroxylase transcription in brainstem catecholamine neurons ${ }^{35}$. These findings suggest that the central GLP-1 action could be involved in the regulation of the sympathetic pathway ${ }^{35}$. However, the identification of GLP-1R expression in mouse atria ${ }^{36}$ and in monkey sinoatrial node ${ }^{37}$ raised the additional possibility that GLP-1 may directly modulate HR through the cardiac GLP-1R. Moreover, Berkelaar et al. evaluated 130 healthy participants undergoing hyperglycaemic clamps and acute exposure to GLP-1 during hyperglycaemia, showing a small acute HR increase without an acute decrease in cardiac vagal control, measured by $\mathrm{HRV}^{38}$. In this setting, serum insulin was positively associated with $\mathrm{HR}^{38}$, suggesting that GLP-1 effect could be mediated by GLP1-driven increase in endogenous insulin ${ }^{39}$. Again, other experimental trials suggested the sympathetic nervous system activation after GLP-1R agonist infusion in healthy individuals ${ }^{40,41}$. All these examples demonstrate that the action of GLP-1R agonist on the sympathetic and parasympathetic systems must be both direct and indirect but this should be further studied with properly designed clinical and experimental trials. Indeed, even the present meta-analytical approach is not able to reach conclusive results, since it is still based on a limited number of studies with small sample size. Thus, the lack of significant effects of GLP-1R agonist chronic administration on ANS might be related to the limited amount of data available so far.

\section{Conclusion}

In conclusion, the present meta-analysis confirms the HR increase but seems to exclude an alteration of the sympatho-vagal balance due to chronic treatment with GLP-1R agonists in people with diabetes. Indeed, despite the accumulating data linking GLP-1R signalling to autonomic and neuroendocrine responses, the neural pathways underlying these actions are not fully understood. Furthermore, considering some discrepancies in the available preclinical and clinical findings, it is conceivable to suggest possible species-specific patterns of GLP-1R, as well as differences among GLP-1R agonists. More information is needed on the mechanisms through which the GLP-1R agonists administration may affect autonomic activity in individuals with diabetes.

\section{Abbreviations}

ANS, autonomic nervous system; BP, blood pressure; CAN, cardiac autonomic neuropathy; CARTs, cardiac autonomic reflex tests; CVOTs, cardiovascular outcome trials; DAN, diabetic autonomic neuropathy; DB, deep breathing; DM, diabetes mellitus; E/I ratio, expiration/inspiration ratio; GLP-1R, glucagon-like peptide 1 receptor; HF, high frequency; HR, heart rate; HRV, heart rate variability; LF, low frequency; LF/HF, low frequency/high frequency; LS, lying-to-standing; MACE, major adverse cardiovascular 
events; T1DM, type 1 diabetes mellitus; T2DM, type 2 diabetes mellitus; RMSSD, square root of the mean squared difference of successive RR intervals; SDNN, standard deviations of RR intervals; VM, Valsalva manoeuvre.

\section{Declarations}

\section{Acknowledgements}

Not applicable.

\section{Authors' contributions}

All authors included in this article made substantial contributions to the data included, as well as assisted with critical revisions of the writing, and approved the final version for submission for publication. CG and DS designed the study, researched, extracted, and analysed data and wrote the manuscript; GB and CP contributed to the discussion and revised the manuscript. MS designed and conducted the study and contributed to the discussion and revised the manuscript. All the authors approved the version to be published.

\section{Funding}

This research did not receive any specific grant from any funding agency in the public, commercial or not-for-profit sector.

\section{Competing interests}

The authors declare no competing interests.

\section{Availability of data and materials}

All data generated or analyzed during this study are included in this published article.

\section{Ethics approval and consent to participate}

Not applicable.

\section{Consent for publication}

Not applicable.

\section{Competing interests}

The authors declare that there is no conflict of interest that could be perceived as prejudicing the impartiality of this systematic review and meta-analysis.

\section{References}

1. Tesfaye, S. et al. Diabetic neuropathies: update on definitions, diagnostic criteria, estimation of severity, and treatments. Diabetes Care 33, 2285-2293, doi:10.2337/dc10-1303 (2010).

2. Spallone, V. et al. Cardiovascular autonomic neuropathy in diabetes: clinical impact, assessment, diagnosis, and management. Diabetes Metab Res Rev 27, 639-653, doi:10.1002/dmrr.1239 (2011).

3. Neil, H. A., Thompson, A. V., John, S., McCarthy, S. T. \& Mann, J. I. Diabetic autonomic neuropathy: the prevalence of impaired heart rate variability in a geographically defined population. Diabet Med 6, 20-24, doi:10.1111/j.14645491.1989.tb01133.x (1989).

4. Ziegler, D., Gries, F. A., Spüler, M. \& Lessmann, F. The epidemiology of diabetic neuropathy. DiaCAN Multicenter Study Group. Diabet Med 10 Suppl 2, 82S-86S, doi:10.1111/j.1464-5491.1993.tb00208.x (1993). 
5. Zoppini, G. et al. Prevalence of Cardiovascular Autonomic Neuropathy in a Cohort of Patients With Newly Diagnosed Type 2 Diabetes: The Verona Newly Diagnosed Type 2 Diabetes Study (VNDS). Diabetes Care 38, 1487-1493, doi:10.2337/dc150081 (2015).

6. Williams, S. M., Eleftheriadou, A., Alam, U., Cuthbertson, D. J. \& Wilding, J. P. H. Correction to: Cardiac Autonomic Neuropathy in Obesity, Metabolic Syndrome and Prediabetes: A Narrative Review. Diabetes Ther 10, 2023, doi:10.1007/s13300-019-00705-z (2019).

7. Spallone, V. Update on the Impact, Diagnosis and Management of Cardiovascular Autonomic Neuropathy in Diabetes: What Is Defined, What Is New, and What Is Unmet. Diabetes Metab J 43, 3-30, doi:10.4093/dmj.2018.0259 (2019).

8. Pop-Busui, R. et al. Diabetic Neuropathy: A Position Statement by the American Diabetes Association. Diabetes Care 40, 136-154, doi:10.2337/dc16-2042 (2017).

9. Vinik, A. I. \& Ziegler, D. Diabetic cardiovascular autonomic neuropathy. Circulation 115, 387-397, doi:10.1161/CIRCULATIONAHA.106.634949 (2007).

10. Drucker, D. J. Mechanisms of Action and Therapeutic Application of Glucagon-like Peptide-1. Cell Metab 27, 740-756, doi:10.1016/j.cmet.2018.03.001 (2018).

11. Cooney, M. T. et al. Elevated resting heart rate is an independent risk factor for cardiovascular disease in healthy men and women. Am Heart J 159, 612-619.e613, doi:10.1016/j.ahj.2009.12.029 (2010).

12. Marso, S. P. et al. Liraglutide and Cardiovascular Outcomes in Type 2 Diabetes. N Engl J Med 375, 311-322, doi:10.1056/NEJMoa1603827 (2016).

13. Pfeffer, M. A. et al. Lixisenatide in Patients with Type 2 Diabetes and Acute Coronary Syndrome. N Engl J Med 373, 22472257, doi:10.1056/NEJMoa1509225 (2015).

14. Marso, S. P. et al. Semaglutide and Cardiovascular Outcomes in Patients with Type 2 Diabetes. N Engl J Med 375, 18341844, doi:10.1056/NEJMoa1607141 (2016).

15. Holman, R. R. et al. Effects of Once-Weekly Exenatide on Cardiovascular Outcomes in Type 2 Diabetes. N Engl J Med 377, 1228-1239, doi:10.1056/NEJMoa1612917 (2017).

16. Hernandez, A. F. et al. Albiglutide and cardiovascular outcomes in patients with type 2 diabetes and cardiovascular disease (Harmony Outcomes): a double-blind, randomised placebo-controlled trial. Lancet 392, 1519-1529, doi:10.1016/S01406736(18)32261-X (2018).

17. Gerstein, H. C. et al. Dulaglutide and cardiovascular outcomes in type 2 diabetes (REWIND): a double-blind, randomised placebo-controlled trial. Lancet 394, 121-130, doi:10.1016/S0140-6736(19)31149-3 (2019).

18. Husain, M. et al. Oral Semaglutide and Cardiovascular Outcomes in Patients with Type 2 Diabetes. N Engl J Med 381, 841851, doi:10.1056/NEJMoa1901118 (2019).

19. Katout, M. et al. Effect of GLP-1 mimetics on blood pressure and relationship to weight loss and glycemia lowering: results of a systematic meta-analysis and meta-regression. Am J Hypertens 27, 130-139, doi:10.1093/ajh/hpt196 (2014).

20. Nyström, T. et al. Effects of glucagon-like peptide-1 on endothelial function in type 2 diabetes patients with stable coronary artery disease. Am J Physiol Endocrinol Metab 287, E1209-1215, doi:10.1152/ajpendo.00237.2004 (2004).

21. Gutzwiller, J. P. et al. Glucagon-like peptide 1 induces natriuresis in healthy subjects and in insulin-resistant obese men. $J$ Clin Endocrinol Metab 89, 3055-3061, doi:10.1210/jc.2003-031403 (2004).

22. Sun, F. et al. Impact of GLP-1 receptor agonists on blood pressure, heart rate and hypertension among patients with type 2 diabetes: A systematic review and network meta-analysis. Diabetes Res Clin Pract 110, 26-37, doi:10.1016/j.diabres.2015.07.015 (2015).

23. England, J. D. et al. Practice Parameter: evaluation of distal symmetric polyneuropathy: role of autonomic testing, nerve biopsy, and skin biopsy (an evidence-based review). Report of the American Academy of Neurology, American Association of Neuromuscular and Electrodiagnostic Medicine, and American Academy of Physical Medicine and Rehabilitation. Neurology 72, 177-184, doi:10.1212/01.wnl.0000336345.70511.0f (2009). 
24. Bernardi, L. et al. Methods of investigation for cardiac autonomic dysfunction in human research studies. Diabetes Metab Res Rev 27, 654-664, doi:10.1002/dmrr.1224 (2011).

25. Brock, C. et al. Liraglutide treatment reduced interleukin-6 in adults with type 1 diabetes but did not improve established autonomic or polyneuropathy. British journal of clinical pharmacology 85, 2512-2523, doi:10.1111/bcp.14063 (2019).

26. Cacciatori, V. et al. Long-Acting GLP-1 Receptor Agonist Exenatide Influence on the Autonomic Cardiac Sympatho-Vagal Balance. J Endocr Soc 2, 53-62, doi:10.1210/js.2017-00300 (2018).

27. Hansen, C. S. et al. Liraglutide-Induced Weight Loss May be Affected by Autonomic Regulation in Type 1 Diabetes. Frontiers in endocrinology 10, 242, doi:10.3389/fendo.2019.00242 (2019).

28. Jaiswal, M. et al. Effects of exenatide on measures of diabetic neuropathy in subjects with type 2 diabetes: results from an 18-month proof-of-concept open-label randomized study. J Diabetes Complications 29, 1287-1294, doi:10.1016/j.jdiacomp.2015.07.013 (2015).

29. Kumarathurai, P. et al. Effects of the glucagon-like peptide-1 receptor agonist liraglutide on 24-h ambulatory blood pressure in patients with type 2 diabetes and stable coronary artery disease: a randomized, double-blind, placebo-controlled, crossover study. J Hypertens 35, 1070-1078, doi:10.1097/hjh.0000000000001275 (2017).

30. Nyström, T. et al. Heart rate variability in type 2 diabetic subjects randomized to liraglutide or glimepiride treatment, both in combination with metformin: A randomized, open, parallel-group study. Endocrinol Diabetes Metab 2, e00058, doi:10.1002/edm2.58 (2019).

31. Kumarathurai, P. et al. Effects of Liraglutide on Heart Rate and Heart Rate Variability: A Randomized, Double-Blind, Placebo-Controlled Crossover Study. Diabetes care 40, 117-124, doi:10.2337/dc16-1580 (2017).

32. Goldstein, D. S., Bentho, O., Park, M. Y. \& Sharabi, Y. Low-frequency power of heart rate variability is not a measure of cardiac sympathetic tone but may be a measure of modulation of cardiac autonomic outflows by baroreflexes. Exp Physio/ 96, 1255-1261, doi:10.1113/expphysiol.2010.056259 (2011).

33. Billman, G. E. The LF/HF ratio does not accurately measure cardiac sympatho-vagal balance. Front Physio/ 4, 26, doi:10.3389/fphys.2013.00026 (2013).

34. Baggio, L. L. et al. The autonomic nervous system and cardiac GLP-1 receptors control heart rate in mice. Mol Metab 6, 1339-1349, doi:10.1016/j.molmet.2017.08.010 (2017).

35. Yamamoto, H. et al. Glucagon-like peptide-1 receptor stimulation increases blood pressure and heart rate and activates autonomic regulatory neurons. The Journal of clinical investigation 110, 43-52, doi:10.1172/jci15595 (2002).

36. Richards, P. et al. Identification and characterization of GLP-1 receptor-expressing cells using a new transgenic mouse model. Diabetes 63, 1224-1233, doi:10.2337/db13-1440 (2014).

37. Pyke, C. et al. GLP-1 receptor localization in monkey and human tissue: novel distribution revealed with extensively validated monoclonal antibody. Endocrinology 155, 1280-1290, doi:10.1210/en.2013-1934 (2014).

38. Berkelaar, M. et al. Effects of induced hyperinsulinaemia with and without hyperglycaemia on measures of cardiac vagal control. Diabetologia 56, 1436-1443, doi:10.1007/s00125-013-2848-6 (2013).

39. Valensi, P., Chiheb, S. \& Fysekidis, M. Insulin- and glucagon-like peptide-1-induced changes in heart rate and vagosympathetic activity: why they matter. Diabetologia 56, 1196-1200, doi:10.1007/s00125-013-2909-x (2013).

40. Bharucha, A. E. et al. Effects of glucagon-like peptide-1, yohimbine, and nitrergic modulation on sympathetic and parasympathetic activity in humans. Am J Physiol Regul Integr Comp Physio/ 295, R874-880, doi:10.1152/ajpregu.00153.2008 (2008).

41. Smits, M. M. et al. Exenatide acutely increases heart rate in parallel with augmented sympathetic nervous system activation in healthy overweight males. Br J Clin Pharmaco/ 81, 613-620, doi:10.1111/bcp.12843 (2016).

\section{Figures}




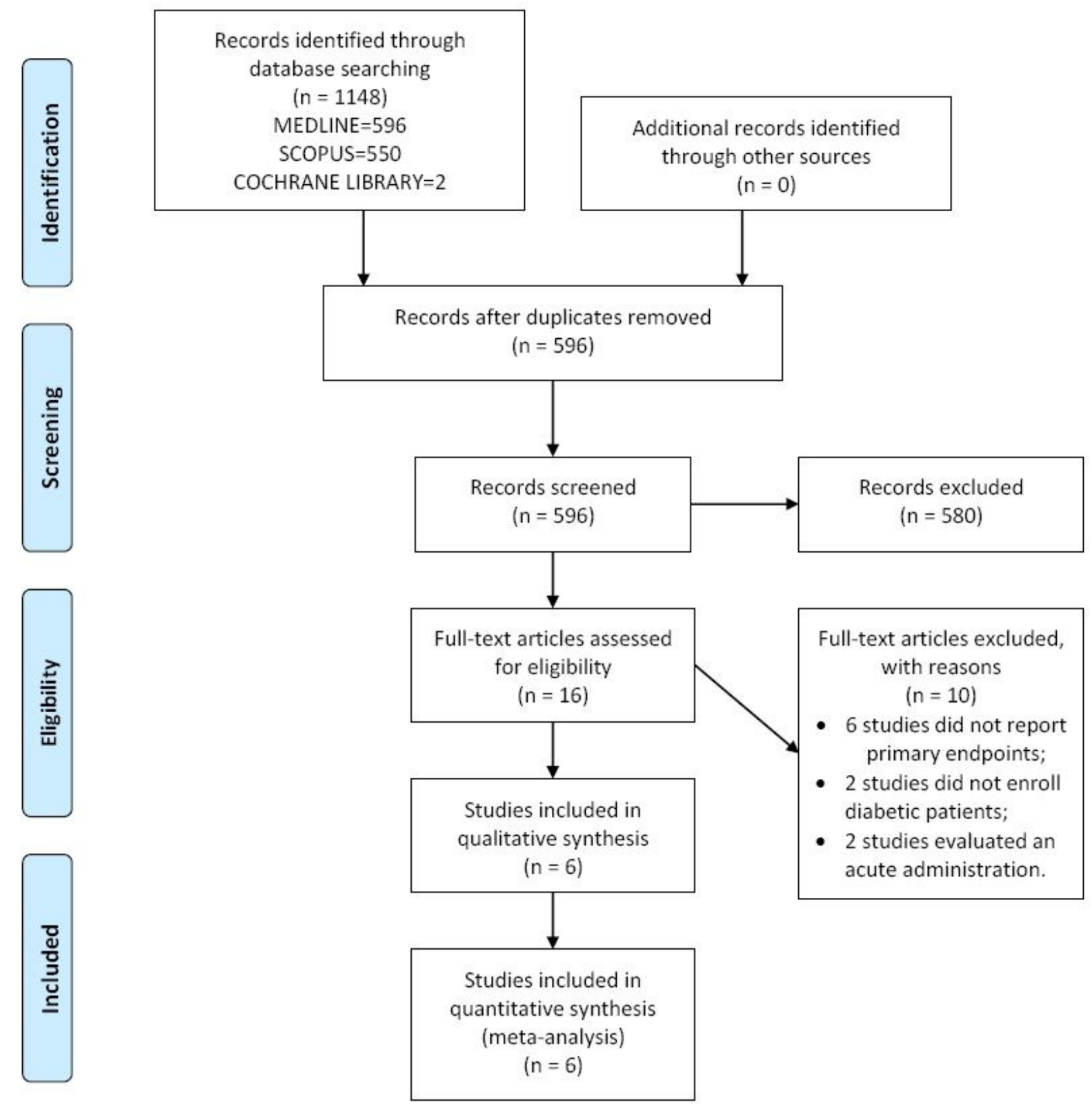

Figure 1

Flow diagram. Flowchart of the study search and selection process. 


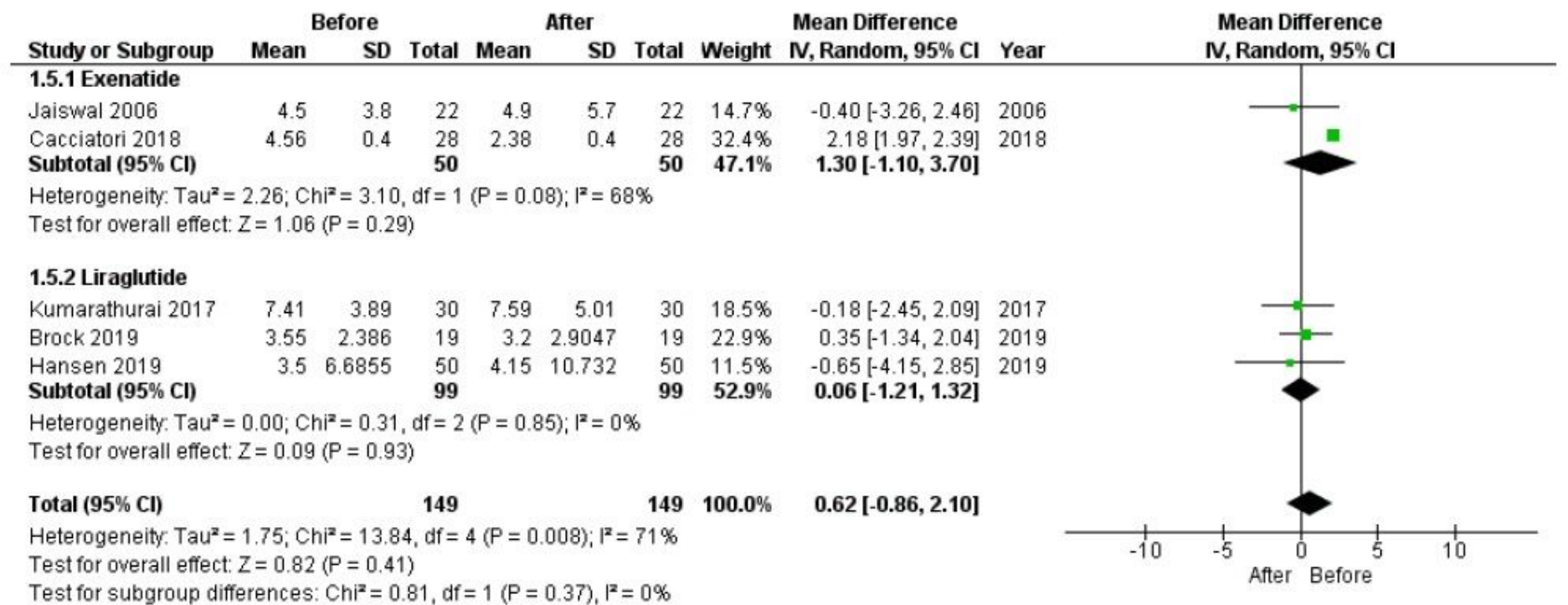

\section{Figure 2}

LF/HF ratio mean difference after the chronic administration of GLP-1R agonists. LF/HF ratio mean difference after treatment in the entire sample $(p=0.410)$ and considering only exenatide $(p=0.290)$ or only liraglutide $(p=0.930)$ treatment. (LF/HF, low frequency/high frequency ratio).

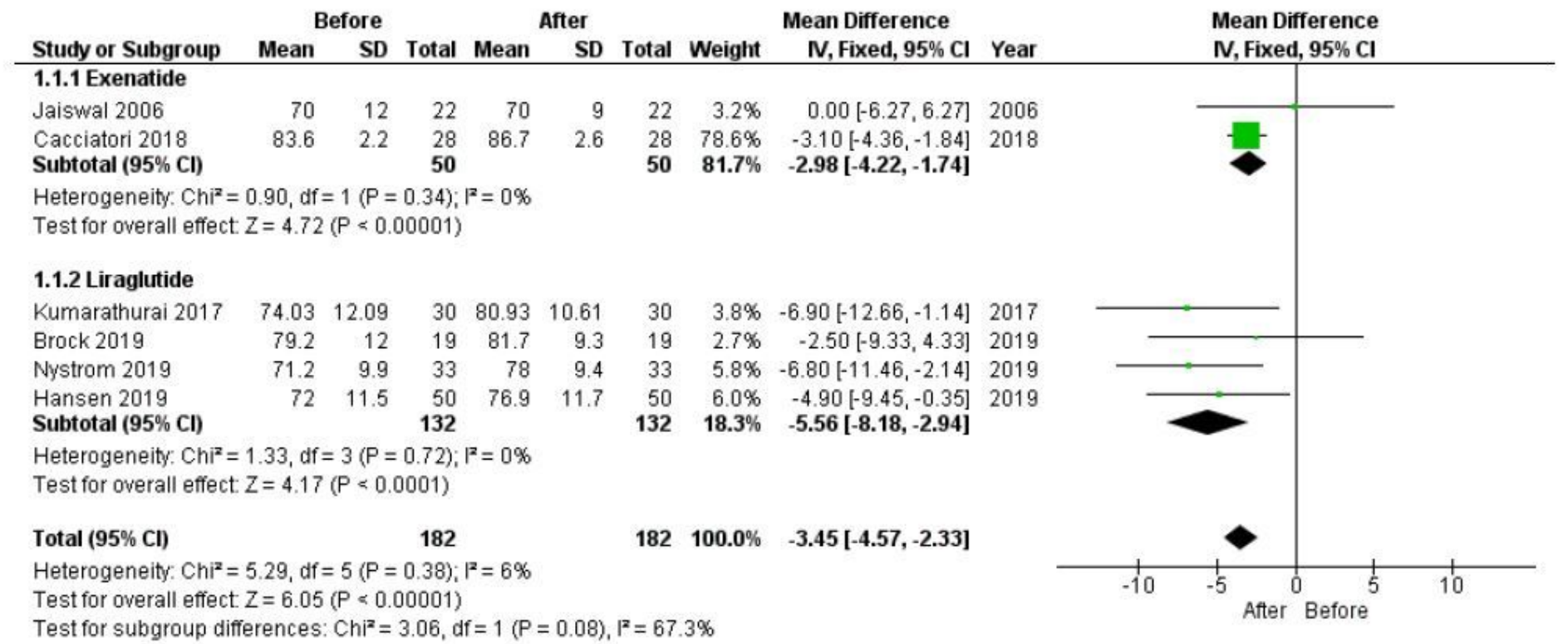

\section{Figure 3}

HR mean difference before and after treatment. HR significantly increases after treatment $(p<0.001)$, with a low heterogeneity rate $(6 \%)$. (HR, heart rate). 


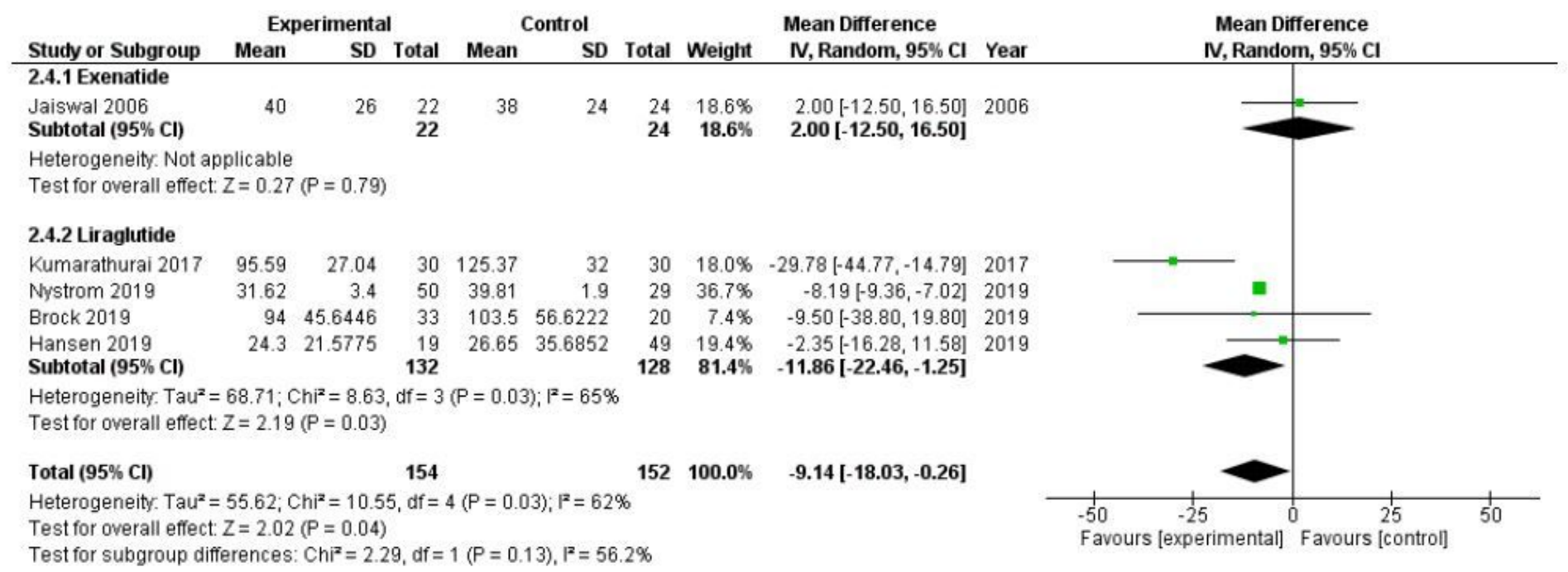

\section{Figure 4}

SDNN mean difference after the GLP-1R chronic administration comparing study and control groups. Significantly lower SDNN values were detected in the study- compared to control groups ( $p=0.040)$. (SDNN, standard deviations of RR intervals).

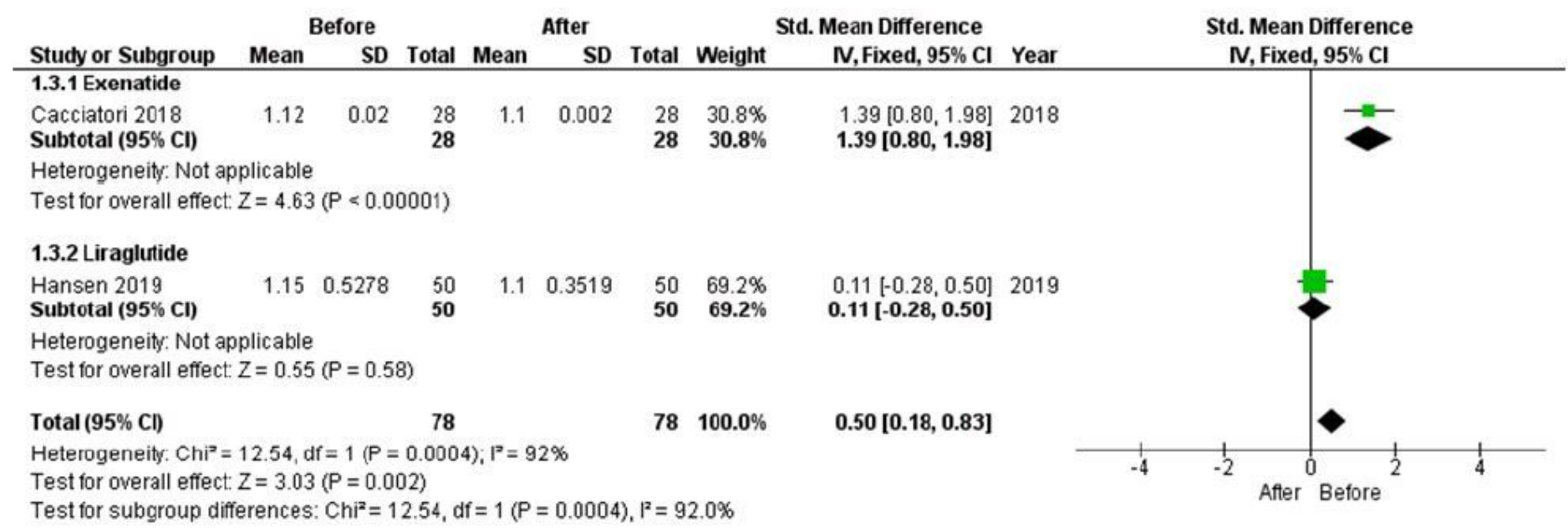

\section{Figure 5}

30:15 value standard mean difference after chronic GLP-1R agonists treatment. 30:15 value after treatment (standard mean difference $0.50 ; 95 \% \mathrm{Cl}: 0.18,0.83, \mathrm{p}=0.002$ ).

\section{Supplementary Files}

This is a list of supplementary files associated with this preprint. Click to download.

- Supplementaryfigurelegends.docx

- Supplementaryfigures.pdf 